\title{
PERGANTIAN SKENARIO OTOMATIS PADA GAME TAJWID MENGGUNAKAN FUZZY SUGENO
}

\author{
Yunifa Miftachul Arif ${ }^{1)}$, Ardi Yulianto ${ }^{2)}$ \\ Jurusan Teknik Informatika \\ Fakultas Sains dan Teknologi, Universitas Islam Negeri Maulana Malik Ibrahim Malang \\ Email : yunif4@gmail.com, ardiek22@gmail.com
}

\begin{abstract}
Abstrak - Game akan menarik dan menyenangkan untuk dimainkan apabila cerita dalam game tersebut dapat memberikan tantangan dengan cerita yang dapat berubah sesuai dengan kondisi pemainnya. Perubahan cerita tersebut dapat membuat rasa penasaran pemain, sehingga dapat menumbuhkan rasa penasaran pemain terhadap game tersebut. Dalam penelitian ini dibahas tentang penerapan fuzzy sugeno dalam perubahan skenario game Tajwid agar pemian di setiap level bisa memainkan skenario yang berbeda. Dalam setiap level terdapat 3 skenario yaitu skenario mudah, menengah dan sulit. Skenario itu didapat dari inputan pemain pada level sebelumnya. Inputan untuk perubahan skenario berupa jumlah score dan jumlah nyawa player. Jadi setiap pemain akan mendapat skenario yang berbeda di level berikutnya dari hasil jumlah score dan jumlah nyawa di level sebelumnya. Fuzzy sugeno ini berfungsi untuk mengatur skenario yang cocok yang akan pemain dapatkan di level berikutnya sesuai inputan yang didapat di level sebelumnya. Genre yang di gunakan dalam penelitian ini adalah RPG (Role Playing Game).
\end{abstract}

Kata kunci : Game, Skenario Game, Fuzzy Sugen, RPGPENDAHULUAN

Dengan berkembangnya teknologi yang semakin pesat saat ini, banyak metode yang dilakukan agar bisa membantu masyarakat dalam memahaminya, seperti pen yang bisa membaca $\mathrm{Al}$ quran dengan menggunakan tajwid. selain alat canggih seperti pena digital di indonesia juga lagi marak berkembangnya dunia multimedia yang sekarang lagi banyak di minati oleh para remaja dan juga anak - anak. Hali ini dibuktikan dengan banyaknya para pengembang game yang ada di seluruh Indonesia.

Dari sini penulis memiliki sebuah inisiatif untuk mengembangkan metode pembelajaran tajwid dengan cara beda yaitu dengan metode bermain game. Dalam penelitian ini game yang akan dibuat adalah game edukasi pembelajaran ilmu tajwid yang bergenre RPG (Role Playing Game). Di dalam game ini setiap levelnya akan memiliki tiga skenario. Dimana dalam setiap tiap skenario diambil dari nyawa dan score pada level sbelumnya. Jadi pengguna tidak akan bosan memaikan game ini karena skenarionya akan berubah-rubah sesuai dengan hasil yang di dapat di level sebelumnya.

Dengan skenario yang berubah - ubah ini diterapka sebuah metode kecerdasan buatan yaitu metode fuzzy sugeno dimana fuzzy sugeno ini yang akan menetapkan skenario mana yang cocok dalam satu level untuk pengguna setelah menyelesaikan level sebelumnya.

\section{LANDASAN TEORI}

A. Pegertian Skenario Game
Skenario adalah urutan yang disusun agar suatu peristiwa terjadi sesuai dengan yang diinginkan. Skenario game adalah langkah awal dalam membuat sebuah game, dengan skenario game dapat mempermudah kita menyelesaikan game yang akan kita buat. Skenario game adalah sebuah cerita khusus yang melatarbelakangi kejadian kejadian dalam game.

\section{B. Ilmu Tajwid}

Lafadz Tajwid menurut bahasa artinya membaguskan. Sedangkan menurut istilah adalah: "Mengeluarkan setiap huruf dari tempat keluarnya dengan memberi hak dan mustahaknya." Yang dimaksud dengan hak huruf adalah sifat asli yang selalu bersama dengan huruf tersebut, seperti AI Jahr, Isti'la', istifal dan lain sebagainya. Sedangkan yang dimaksud dengan mustahak huruf adalah sifat yang nampak sewaktu-waktu, seperti tafkhim, tarqiq, ikhfa' dan lain sebagainya.

\section{Fuzzy Sugeno}

Penalaran dengan metode SUGENO hampir sama dengan penalaran MAMDANI, hanya saja output (konsekuen) sistem tidak berupa himpunan fuzzy, melainkan berupa konstanta atau persamaan linear. Metode ini diperkenalkan oleh TakagiSugeno Kang pada tahun 1985.

- Model Fuzzy Sugeno Orde-Nol

Secara umum bentuk model fuzzy SUGENO Orde-Nol adalah: 
$\mathrm{IF}(\mathrm{x} 1$ is $\mathrm{A} 1)$ o ( $\mathrm{x} 2$ is $\mathrm{A} 2)$ o $(\mathrm{x} 3 \text { is } \mathrm{A} 3)^{\circ} \mathrm{o}$ ..... $\mathrm{o}(\mathrm{xN}$ is $\mathrm{AN})$ THEN $\mathrm{z}=\mathrm{k}$

dengan $\mathrm{Ai}$ adalah himpunan fuzzy ke-i sebagai anteseden, dan $\mathrm{k}$ adalah suatu konstanta (tegas) sebagai konsekuen.

- Model Fuzzy Sugeno Orde-Satu

Secara umum bentuk model fuzzy SUGENO Orde-Satu adalah:

IF ( $\mathrm{x} 1$ is $\mathrm{A} 1)$ o ...... o ( $\mathrm{xN}$ is $\mathrm{AN})$ THEN $\mathrm{z}$ $=\mathrm{p} 1 * \mathrm{x} 1+\ldots+\mathrm{pN} * \mathrm{xN}+\mathrm{q}$

dengan $\mathrm{Ai}$ adalah himpunan fuzzy ke-i sebagai anteseden, dan pi adalah suatu konstanta (tegas) ke-i dan q juga merupakan konstanta dalam konsekuen.

Apabila komposisi aturan menggunakan metode SUGENO, maka deffuzifikasi dilakukan dengan cara mencari nilai rata-ratanya.

\section{METODE PENELITIAN}

Fuzzy sugeno yang akan dirancang dalam penelitian ini, mempunyai 2 variabel linguistik sebagai penentu perubahan skenario secara otomatis yaitu banyaknya Score dan banyaknya Life atau nyawa yang didapat player. Nantinya Variabel itu akan menentukan bagaimana skenario yang akan di dapat oleh player di tiap level berikutnya. Untuk inputan Score dan Life disini dianggap sebagai inputan berupa konstanta yang tetap dan memeliki output dengan kosntanta yang tetap pula. Sknenario pada level yang sama terbagi dalam 3 kategori :
a. Skenario A (Mudah)
b. Skenario B (Menengah)
c. Sknario C (Sulit)

Variabel penentu skenario otomastis diantaranya :
A. Variabel Score

Score adalah bonus yang didapat player setalah berhasil menjawab pertanyaan. Score disini berbentuk angka bulat. Score maximal adalah score tertuggi yang di dapat oleh player. Berikut adalah derajat keanggotaan :

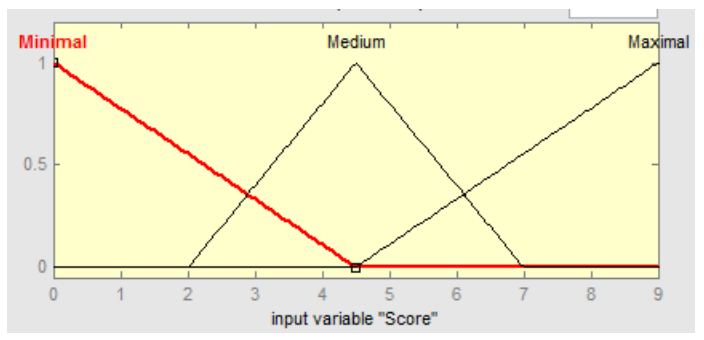

Gambar 3.2 Derajat keanggotaan Variabel Score

B. Variabel Life (nyawa)

Life adalah Sisa nyawa yang di dapat player setelah berhasil menjalankan misi. Berikut derajat keanggotaan variabel life :

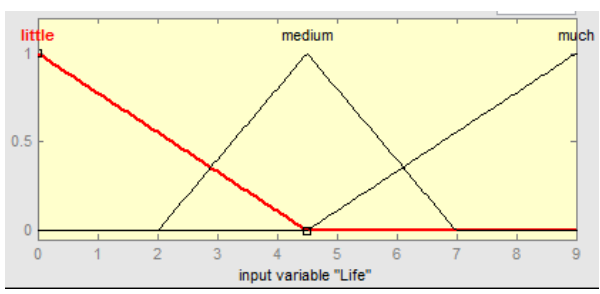

Gambar 3.3 Derajat keanggotaan variabel Life atau nyawa

\section{HASIL DAN PEMBAHASAN}

A. Game dan Karakter

Genre game yang dibuat pada penelitian ini menggunakan Role Playing Game (RPG). Tampilan user interface game tajwid pada penelitian ini adalah sebagai berikut.

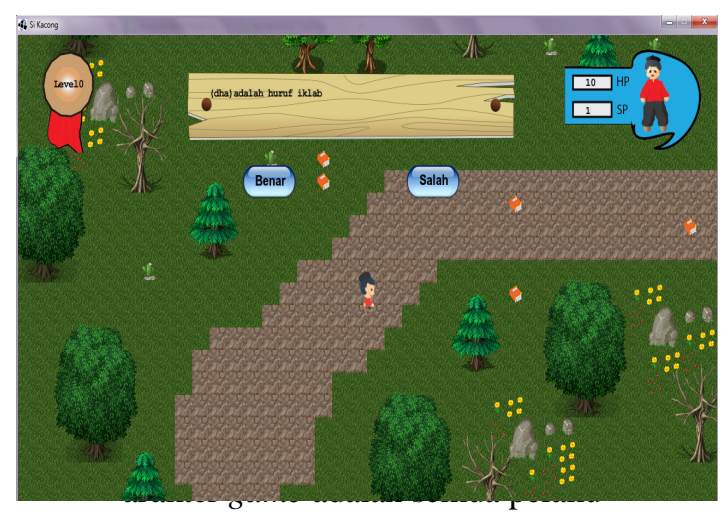

yang ikut terlibat dalam skenario game. Jenis karakter dalam game dalam game bermacam macam ada karakter pemain utama, NPC (Non Player Charakter), dan lain-lain. Adapun karakter dalam game ini adalah sebagai berikut :

Avatar atau karakter utama dalam permainan ini adalah si kacong. Sikacong memakai baju muslim berwarna merah, becelana hitam, dan memakai kopiah berwarna hitam.

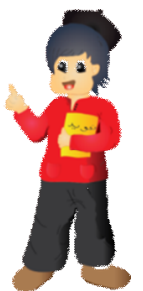

Gambar 4.2 Avatar (Si Kacong)

Karakter kaktus adalah karakter dimana jika avatar menabraknya maka point nyawa avatar akan berkurang.

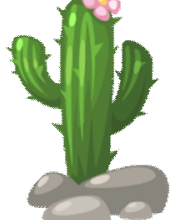

Gambar 4.3 Karakter Kaktus 
Karakter kitab adalah karakter yang berwarna kuning. Pemain utama akan mencari karakter ini nantinya agar point bonus bisa bertambah.

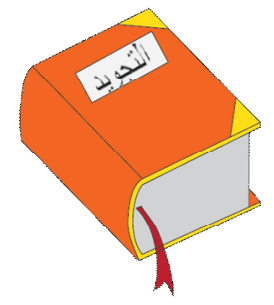

Gambar 4.4 Karakter Kitab

B. Implementasi Fuzzy Sugeno dalam Skenario Game

Pada implementasi fuzzy sugeno, ada beberapa langkah dalam pemecahannya. dalam perhitungan untuk mengetahui output menggunakan operasi tuple .Dalam kasus ini akan dijelaskan contoh dalam penghitungannya. Untuk contoh kasusnya adalah sebuah player mendapat jumlah score 5 dan jumlah life 7 jadi level yang di dapat adalah sebagai berikut :

\section{Derajat Keanggotan}

Untuk inputan yang di dapat oleh player akan di masukkan ke dalam fungsi derajat anggotaan ini. Untuk derajat keanggotaannya adalah sebagai berikut :

Untuk Score :

$$
\begin{aligned}
& \text { Hareminimal }=\left\{\begin{array}{c}
5.5-x \\
\frac{5.5-1}{0} ; x \geq 5.5
\end{array}\right. \\
& \text { Horemedium }=\left\{\begin{array}{l}
0,3 \leq 3 \text { atau } x \geq 8 \\
\frac{x-3}{5.5-3} ; 3 \leq x \leq 5.5 \\
\frac{8-x}{8-5.5} ; 5.5 \leq x \leq 10
\end{array}\right. \\
& H_{\text {scoremaximal }}=\left\{\begin{array}{c}
0, x \leq 5.5 \\
\frac{x-5.5}{10-5.5} ; 5.5 \leq x \leq 10 \\
1 ; x \geq 10
\end{array}\right.
\end{aligned}
$$

Untuk Life atau Nyawa :

$$
\begin{aligned}
& \mu_{\text {life faw }}=\left\{\begin{array}{c}
\frac{5.5-x}{5.5-1} ; 1 \leq x \leq 5.5 \\
0 ; x \geq 5.5
\end{array}\right. \\
& \mu_{\text {iife madium }}=\left\{\begin{array}{l}
0: 3 \leq 3 \text { atau } x \geq 8 \\
\frac{x-3}{5.5-3} ; 3 \leq x \leq 5.5 \\
\frac{8-x}{8-5.5} ; 5.5 \leq x \leq 10
\end{array}\right.
\end{aligned}
$$

$$
\text { Hife wuch }_{\text {if }}=\left\{\begin{array}{c}
0 ; x \leq 5.5 \\
\frac{x-5.5}{10-5.5} ; 5.5 \leq x \leq 10 \\
1 ; x \geq 10
\end{array}\right.
$$

\section{Fuzzifikasi}

Berikut hasil dari fuzzifikasinya : Untuk Score :

$$
\begin{aligned}
& \mu_{\text {score minimal }}: \frac{5.5-5}{5.5-1}=0.11 \\
& \mu_{\text {score medium }}: \frac{5-3}{5.5-3}=0.8 \\
& \mu_{\text {seore maximal }} 0
\end{aligned}
$$

Untuk Life :

$$
\begin{aligned}
& \mu_{\text {score minimal }}: 0 \\
& \mu_{\text {score medium }}: \frac{8-7}{8-5.5}=0,4 \\
& \mu_{\text {score maximal }}: \frac{7-5.5}{10-5,5}=0,33
\end{aligned}
$$

\section{Implikasi}

Dari hasil fuzzifikasi, dibuatlah sebuah rule dari aturan game ini yaitu :
a. IF score_min AND life_few THEN Skenario A
b. IF score_min AND life_med THEN Skenario A
c. IF score_min AND life_much THEN Skenario B
d. IF score_med AND life_few THEN Skenario $\mathrm{B}$
e. IF score_med AND life_med THEN Skenario $\mathrm{B}$
f. IF score_med AND life_much THEN Skenario C
g. IF score_max AND life_few THEN Skenario C
h. IF score_max AND life_med THEN Skenario C
i. IF score_max AND life_max THEN Skenario $\mathrm{C}$
Rule diatas akan dimasukkan dalam tabel operasi tuple sebgai berikut :

\section{Defuzzifikasi}

Dari hasil minimisasi masing-masing tuple, didapatkan $f$ dengan anggota himpunan output beserta nilai derajat keanggotaan, sebagai berikut :

\section{$f=\{A, B, B, C\}=\{0,11 ; 0,11 ; 0,4 ; 0,33\}$}

Sehingga dengan metode max method dicari index tertinggi dari $f$ yang akan menghasilkan nilai keluaran $(k)$ yang kemudian 
menentukan blok skenario mana yang cocok dari ke-4 relasi aturan tersebut

$$
\begin{aligned}
& k=\max (f) \\
& k=\max (\boldsymbol{A}, \boldsymbol{B}, \boldsymbol{B}, \boldsymbol{C}) \\
& k=\max (0,11 ; 0,11 ; 0,4 ; 0,33) \\
& k=\mathbf{0 , 4}==\mathbf{-} \text { B }
\end{aligned}
$$
pengujian dari beberapa inputan yang akan menghasilkan skenario yang berbeda di level selanjutnya. Pengujian ini diambil dari inputan pada level 0 . Untuk kolom yang diberi warna merah menjelaskan tentang jumlah point life yang di dapat oleh player dan untuk kolom warna hijau tua menjelaskan jumlah point score yang didapat oleh player. Untuk batas jumlah inputan life dan score dibatasi maksimal 10 point. Berikut adalah tabel hasil pengujiannya :

Tabel 4.1 Pengujian Fuzzy Sugeno

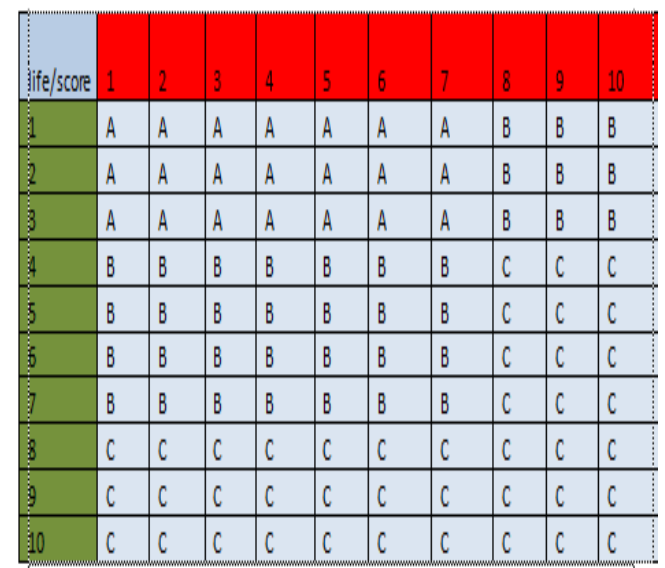

Pada pengujian tabel pengujian dijelaskan bahwa penerapan logika fuzzy berfungsi sebagai penentu perubahan skenario pada level berikutnya. Tabel 4.1 menjelaskan pada saat player mendapat jumlah point life 1 didalam tabel digambarkan pada kolom warna merah dan player mendapatkan jumlah point score 5 di dalam tabel dijelaskan pada kolom warna hijau tua maka hasil dari pengujian player mendapatkan hasil skenario $\mathrm{C}$ yang ada pada kolom berwarna biru muda dan seterusnya. Inputan penentu dari logika fuzzy sugeno sendiri yaitu banyak atau sedikitnya jumlah point life dan point score yang di dapat oleh player setelah selesai misi pada level sebelumnya. Dan hasilnya sesuai dengan rule yang dibuat sebelumnya.

\section{KESIMPULAN DAN SARAN}

\section{Kesimpulan}

Sesuai dengan hasil uji coba yang telah dilakukan bahwa penerapan metode fuzzy sudah berjalan dengan baik dimana saat player mendapat poin life rendah maka skenarioa level selanjutnya akan mendapat skenario level yang mudah, jika player mendapat point life yang sedang maka player akan mendapat skenario level yang sedang dan apabila mendapat point life yang tinggi maka player akan mendapat skenario level yang sulit sesuai dengan kemampuan player yang sudah di dapat di level sebelumnya.

\section{Saran}

Untuk pengembangakn game ini yang akan datang disarankan untuk :

a. Menambahkan metode fuzzy pada perilaku musuh dengan variabel inputan yang sudah ada sehingga bisa membuat player lebih tertantang saat memainkan game ini.

b. Menambahkan NPC baik agar bisa membantu player dalam menjalankan misi. Dengan ini lebih membuat game ini terlihat lebih menarik

\section{REFERENSI}

[1] Arif, Yunifa Miftachul. Miftachul, F. Kurniawan, F. Nugroho. "Desain Perubahan Perilaku pada NPC Game Menggunakan Logika Fuzzy". Seminar on Electrical, Informatics and Education, 2011, p. A2.110 - A2.111

[2] Arif, Yunifa Miftachul, Ady Wicaksono, dan Fachrul Kurniawan.2012.Pergantian Senjata NPC pada Game FPS Menggunakan Fuzzy Sugeno. Paper telah dipublikasi. Jombang: Unipdu Jombang

[3] Supeno, Mardi S.N dan Moch Hariadi.2012.Aplikasi Modified Improved Particle Swarm Optimazation untuk Skenario Dinamik pada Game Matematika. Paper telah dipublikasi. Jakarta : Universitas Islam Indonesia.

[4] Purba, Kristo Radion, Rini Nur Hasanah dan M. Azis Muslim. 2013. Implementasi Logika Fuzzy Untuk Mengatur Perilaku Musuh dalam Game Bertipe Action-RPG. Paper telah dipublikasi. Malang : Universitas Brawijaya Malang

[5] Kusumadewi, Sri dan Hari Purnomo.2004.Aplikasi Logika Fuzzy untuk Pendukung Keputusan. Yogyakarta : Graha Ilmu

[6] Kusumadewi, Sri. 2002. Analisis Desain Sistem Fuzzy Menggunakan Tool Box Matlab. Yogyakarta : Graha Ilmu

[7] Rizky, Soetan. 2007. Interaksi Manusia dan Komputer. Yogyakarta : Graha Ilmu

[8] Bashori ,Al Ustadz Abu Hazim bin Muhammad.Panduan Praktis Tajwid \& Bid'ah-bid'ah Seputar Al Qur'an serta 250 Kesalahan dalam Membaca AlFatihah.Magetan: Maktabah Daarul Atsar 
[9] Jamzuriy, Syaikh Sulaiman Bin Hasan Al. 2010. Terjemah Tuhfathul Athfaal Pengantar Ilmu Tajwid. Maktabah Ar Razin [10] alifmagz. Membaca Alquran Tanpa Tajwid, Apa Hukumnya?. http://oto.detik.com/read/2014/07/18/070031 12640743/1254/membaca alquran-tanpatajwid-apa-hukumnya diakses pada tanggal 11 September 2014 jam 20.00

[11] Yunanto Wiji Utomo. Pena Digital Pembaca Al Quran Dapat Rekor MURI.

[12] http://tekno.kompas.com/read/2010/12/21/18 584078/Pena. Digital.

Pembaca.Al.Quran.Dapat.Rekor.MURI. diakses pada tanggal 11 September 2014 jam 20.22
[13] M. Imaduddin Al Hakim. HMI Cabang Palembang Gelar Launching Kelas

$$
\text { Tajwid dan Fiqh }
$$

Mingguan.

http://media.kompasiana.com/new-

[14] Dwiperdana. Hasil Survey Gamer Indonesia - Februari 2012. http://agatestudio.com/blog/2012/02/hasilsurvey-gamer-indonesia-februari-2012/ diakses pada tanggal 26 Februari jam 13.05 